\title{
Does Beta-lactam Pharmacokinetic Variability in Critically III Patients Justify Therapeutic Drug Monitoring? A Systematic Review
}

\author{
Fekade Bruck Sime ${ }^{1,2}$, Michael S Roberts ${ }^{1,2,3}$, Sandra L Peake ${ }^{4}$, Jeffrey Lipman ${ }^{5,6}$ and Jason A Roberts ${ }^{1,5,6,7^{*}}$
}

\begin{abstract}
The pharmacokinetics of beta-lactam antibiotics in intensive care patients may be profoundly altered due to the dynamic, unpredictable pathophysiological changes that occur in critical illness. For many drugs, significant increases in the volume of distribution and/or variability in drug clearance are common. When "standard" beta-lactam doses are used, such pharmacokinetic changes can result in subtherapeutic plasma concentrations, treatment failure, and the development of antibiotic resistance. Emerging data support the use of beta-lactam therapeutic drug monitoring (TDM) and individualized dosing to ensure the achievement of pharmacodynamic targets associated with rapid bacterial killing and optimal clinical outcomes. The purpose of this work was to describe the pharmacokinetic variability of beta-lactams in the critically ill and to discuss the potential utility of TDM to optimize antibiotic therapy through a structured literature review of all relevant publications between 1946 and October 2011. Only a few studies have reported the utility of TDM as a tool to improve beta-lactam dosing in critically ill patients. Moreover, there is little agreement between studies on the pharmacodynamic targets required to optimize antibiotic therapy. The impact of TDM on important clinical outcomes also remains to be established. Whereas TDM may be theoretically rational, clinical studies to assess utility in the clinical setting are urgently required.
\end{abstract}

Keywords: Pharmacokinetics, Pharmacodynamics, Beta-lactam, Antibiotics, Therapeutic drug monitoring, Critically ill

\section{Review}

\section{Introduction}

Emerging evidence suggests that optimizing antibiotic dosing may be a key intervention to improve outcomes in patients with sepsis and septic shock [1-7]. Nonetheless, dose optimization in this critically ill population remains a significant clinical challenge.

Pathophysiological alterations associated with critical illness can lead to both an increase in the apparent volume of distribution of an antibiotic as well as in clearance; thus potentially leading to subtherapeutic plasma concentrations at the site of infection, treatment failure, and the development of antibiotic resistance [8-11]. Conversely, the development of renal and/or hepatic

\footnotetext{
*Correspondence: j.roberts2@uq.edu.au

${ }^{1}$ School of Pharmacy and Medical Sciences, University of South Australia,

Adelaide, Australia

${ }^{5}$ Burns, Trauma, and Critical Care Research Centre, The University of

Queensland, Herston, Brisbane, QLD, Australia

Full list of author information is available at the end of the article
}

impairment may be associated with the rapid onset of toxic drug concentrations.

Despite considerable knowledge of the potential issues associated with inadequate antibiotic dosing and the consequences of therapeutic failure, clinicians have little data to guide practice. Although antibiotics are administered frequently in the critically ill [12], to date only a limited number of pharmacokinetic (PK) studies have been undertaken. Instead, the focus has largely been on the avoidance of toxicity from elevated drug concentrations. Accordingly, the available dosing guidelines often are based on PK data obtained from healthy volunteers or noncritically ill patients, with little consideration for the sepsis-induced PK changes that may occur [13]. Moreover, interindividual PK variability in the critically ill, and the consequent unpredictability of drug concentrations, suggests that an empirical fixed dose strategy is unlikely to be successful $[14,15]$. 
Although there is a good understanding of the role for therapeutic drug monitoring (TDM) to optimize dosing for drugs with a narrow therapeutic index (e.g., aminoglycosides, glycopeptides), limited data are available regarding TDM of antibiotics with wider therapeutic indices, such as the beta-lactam class of antibiotics [13]. TDM for these antibiotics has been traditionally seen as unnecessary. However, recent data suggest that there is a relationship between beta-lactam antibiotic target exposure and clinical outcomes in the critically ill. In addition, the reported PK variability of these antibiotics suggests that many patients do not achieve their target exposures.

Although published opinion supports the use of TDM to optimize antibiotic therapy for drugs not traditionally subject to TDM (i.e., beta-lactams) [15-17], this role has not been subjected to a structured literature review.

\section{Purpose}

The purpose of this review is to describe the PK variability of beta-lactam antibiotics and to discuss the potential utility of TDM to optimize therapy for critically ill patients.

\section{Search strategy and results}

Medline (1946 to October 2011), Embase (1947 to October 2011), and the Cochrane Central Registry of Controlled Trials databases were searched for key words to extract data. The search terms were: (1) Pharmacokinetic $^{*}$, pharmacodynamic*, concentration*, clearance, volume of distribution, target concentration intervention, therapeutic drug monitoring, therapeutic drug management, dosing, dose, kinetics; (2) beta-lactam*, antimicrobial*, antibacterial ${ }^{*}$, antibiotic*, ampicillin, dicloxacillin, penicillin, flucloxacillin, piperacillin, cephalothin, cefazolin, ceftriaxone, ceftazidime, cefepime, meropenem, ertapenem and; (3) intensive care, critically ill, critical illness, critical care, sepsis, septic shock, h(a) emofiltration, intermittent hemodialysis, extended dialysis, sustained low-efficiency dialysis, slow-flow dialysis. Each search was limited to the English language and human studies. Finally searches (1), (2), and (3) were combined. Studies from the extensive files of the authors also were eligible for inclusion. A total of 158 original research articles describing the PK and pharmacodynamics (PK/PD) of beta-lactam antibiotics in critically ill patients were reviewed for qualitative synthesis (Figure 1). A relatively large number of studies related to the PK/PD of cefepime, ceftazidime, meropenem, and piperacillin in the critically ill. However, there was limited published data for many commonly prescribed antibiotics, which tend to be of narrower spectrum (i.e., ampicillin, cephalothin, cefazolin, ceftriaxone, dicloxacillin, ertapenem, flucloxacillin, penicillin; Figure 2).

\section{PK/PD variability of beta-lactam antibiotics in the critically ill}

Significant, unpredictable, beta-lactam PK variability is well-documented in the critically ill (Table 1). Increase in the volume of distribution (potentially by several-fold) is common [18-27] primarily due to expansion of the extracellular fluid volume (edema). Elimination half-life also can be prolonged due to the increased volume of distribution [21,28-30]. Conversely, clearance may be unchanged [21], decreased [20,22] or even elevated as a result of augmented renal clearance (ARC) in the hyperdynamic phase of sepsis (resulting in sub-therapeutic concentrations of renally cleared antibiotics) [24-26,31]. Enhanced elimination also can be due to a hypoalbuminemia-related reduction in protein binding, particular for highly bound antibiotics, such as flucloxacillin and ceftriaxone [27,28,32].

Whereas some studies have reported achievement of PD targets in the critically ill with standard beta-lactam dosing strategies used for noncritically ill patients $[20,40,41]$, many others have demonstrated that such empiric antibiotic dosing is insufficient to achieve appropriate PD targets [20,26,27,36,42-48]. These divergent reports reflect the significant interpatient PK variability that occurs in the critically ill. Treatment failure with inappropriate dosing is of particular concern for pathogens with a high minimum inhibitory concentration (MIC) $[14,49]$. Septic patients also may benefit from higher doses, particularly in the initial 24-48 hours of therapy $[38,42,43,50]$. Of note, however, even with an increased dose, the attainment of PD targets may still be unreliable, because beta-lactams have predominantly timedependent kill characteristics, i.e., the time that the unbound (or free) concentration is above the MIC $\left(f \mathrm{~T}_{>\mathrm{MIC}}\right)$ is the major $\mathrm{PK} / \mathrm{PD}$ index associated with bacterial killing [51-53]. Consequently, the goal of betalactam dosing is to optimize the duration of exposure above the MIC during the dosing interval. Increased time above MIC may be achieved by more frequent dosing or by changing the mode of administration from an intermittent bolus injection to either an extended or continuous infusion. The PK of beta-lactam continuous infusions has been most extensively studied for ceftazidime [35,54-59]. However, the clinical superiority of a continuous infusion (versus intermittent injection) for betalactams is yet to be established [60].

A further consideration for optimizing antibiotic exposure relates to antibiotic penetration into the interstitial fluid (ISF) of tissues, which is the site of most infections. Data show antibiotic concentrations in ISF that are two- to tenfold lower than plasma concentrations, suggesting that higher plasma concentrations may be required to ensure target concentrations in ISF $[11,61,62]$. To our knowledge, no studies have adjusted 


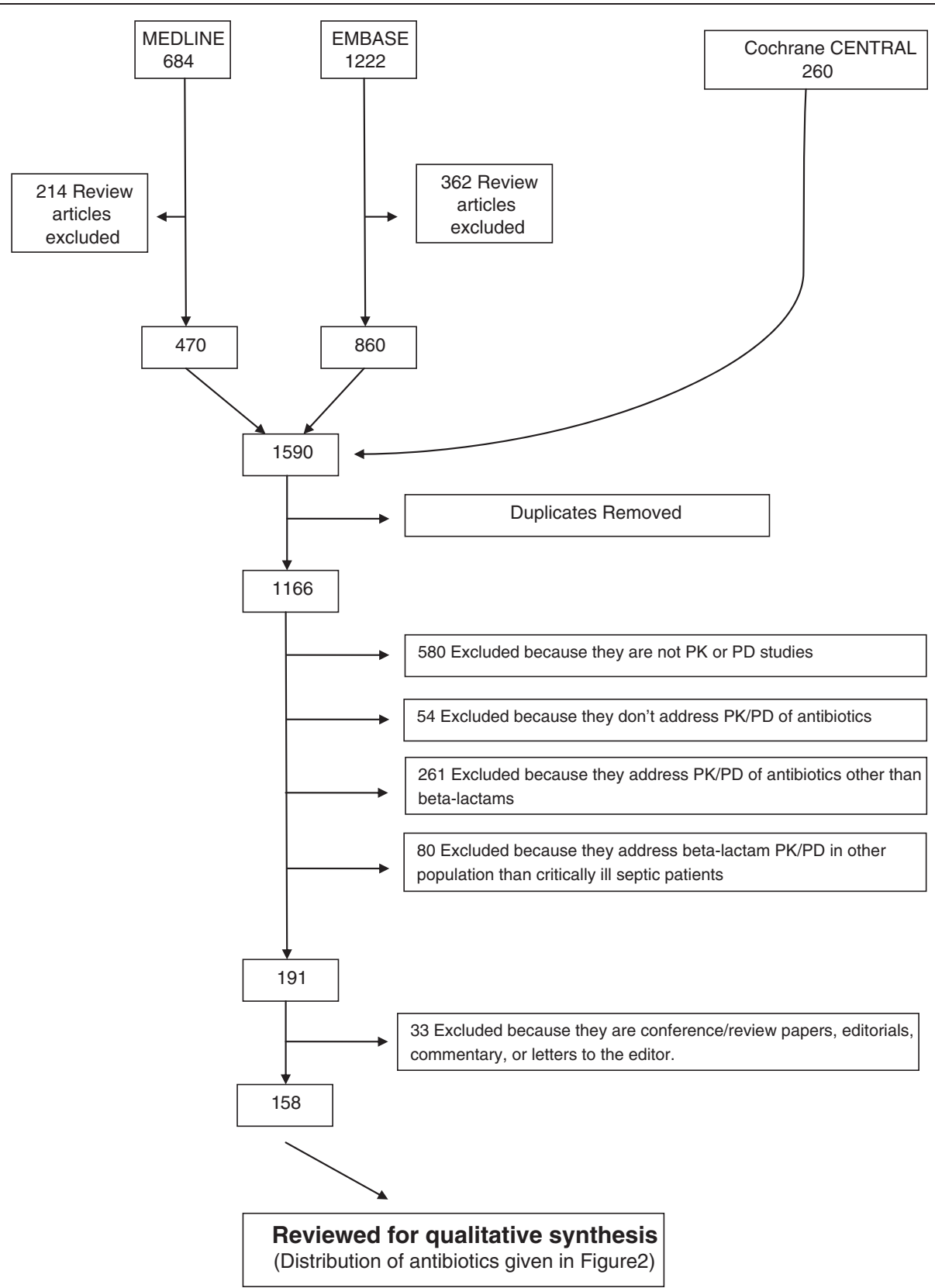

Figure 1 Identification, screening, and selection of articles for the systematic review.

antibiotic doses based on presumed ISF distribution. Problematic to such an approach is that antibiotic concentrations appears to vary between different tissues, suggesting that different plasma target concentrations may be required for the same bacteria depending on the tissue that is the source of infection.

\section{PK alterations in acute kidney injury}

Acute kidney injury occurs in approximately $5 \%$ of critically ill patients and results in significant PK variability for many beta-lactams. Clearance may be extensively reduced, leading to both drug accumulation and toxicity [63-65]. In patients receiving continuous renal replacement therapy (CRRT), extracorporeal clearance is significant, yet variable. Efficient clearance of cefepime [66-68], ceftazidime [69,70], meropenem [71-73], and piperacillin $[74,75]$ has been reported. Ceftriaxone clearance also has been shown to be higher than expected [76,77]. In contrast, CRRT clearance for the highly protein-bound flucloxacillin is minimal $[78,79]$.

It should be noted, however, that it is difficult to compare the reported PK parameters in CRRT studies due to 


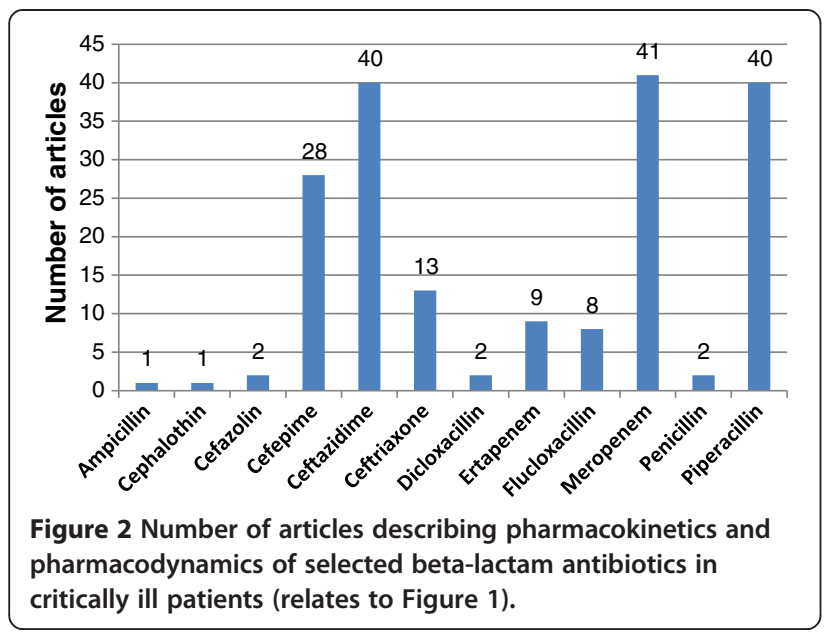

the significant heterogeneity in types of membranes used, operational parameters, and modes of dialysis (Table 2). The consequent unreliable beta-lactam dose prediction for individual patients $[80,81]$ is further compounded by both the limited number of patients studied to date (Table 2) and the fact that different studies cite different PD targets. Finally, the contribution of CRRT to total clearance is variable and dependent on the degree of intrinsic renal function and potential other organ dysfunction $[82,83]$. As a consequence, there are no definitive dosing guidelines that can be used for all critically ill patients who undergo CRRT. More importantly, some of the current dosing recommendations have been shown to be inadequate, particularly against resistant organisms $[69,84]$, whereas toxicity from unnecessarily high concentrations also has been reported $[63-65,82,85]$.

Is there a role for beta-lactam TDM in the critically ill? Do beta-lactams meet the traditional criteria for requiring TDM?

Drugs that are traditionally viewed as appropriate candidates for TDM fulfill one or more of the criteria listed in Table 3. Notably, much of the focus of these criteria is

Table 1 Pharmacokinetic parameters of selected beta-lactam antibiotics in critically ill patients without renal dysfunction

\begin{tabular}{|c|c|c|c|c|c|c|c|c|c|c|}
\hline Antibiotic & Patients & Dose & $\begin{array}{l}\mathrm{Vd} \\
(\mathrm{l} / \mathrm{kg})\end{array}$ & $\begin{array}{l}\mathrm{CL} \\
(\mathrm{ml} / \mathrm{min})\end{array}$ & $\begin{array}{l}T_{1 / 2} \\
\text { (h) }\end{array}$ & $\begin{array}{l}\mathrm{C}_{\max } \\
(\mathrm{mg} / \mathrm{ml})\end{array}$ & $\begin{array}{l}\text { AUC } \\
\text { (mg.h/L) }\end{array}$ & $\begin{array}{l}\text { MIC targeted } \\
(\mathrm{mg} / \mathrm{L})\end{array}$ & $\begin{array}{l}\text { PD target } \\
\text { achieved }\end{array}$ & Reference \\
\hline \multirow[t]{6}{*}{ Cefepime } & 12 & $2 \mathrm{~g} \mathrm{q} 12 \mathrm{~h}$ & $0.34^{*}$ & 123 & 3.2 & & 346 & 4 & $77 \% \mathrm{~T}>\mathrm{MIC}$ & {$[18]$} \\
\hline & 19 & $2 \mathrm{~g} \mathrm{q} 8 \mathrm{~h}$ & 0.36 & $88.2^{*}$ & 3.37 & 68 & 310 & 32 & $34 \% \mathrm{~T}>4 \times \mathrm{MIC}$ & [20] \\
\hline & 13 & $2 \mathrm{~g} \mathrm{q} 12 \mathrm{~h}$ & $0.32^{*}$ & 134 & 2.5 & & 249 & & & [33] \\
\hline & 7 & $2 \mathrm{~g} \mathrm{q} 12 \mathrm{~h}$ & $0.47^{*}$ & 125 & 3.42 & & 305 & 7 & $80 \% \mathrm{~T}>\mathrm{MIC}_{90}$ & [19] \\
\hline & & & & & & & & 5 & $100 \% \mathrm{~T}>\mathrm{MIC}_{90}$ & \\
\hline & 17 & $2 \mathrm{~g} \mathrm{q} 8 \mathrm{~h}$ & 0.37 & $88.2^{*}$ & 3.37 & 66.56 & 324.02 & & & [34] \\
\hline \multirow[t]{6}{*}{ Ceftazidime } & 15 & $2 \mathrm{~g} \mathrm{q} 8 \mathrm{~h}$ & $0.81^{*}$ & 151 & 4.75 & & 277.31 & & & [21] \\
\hline & 12 & $2 \mathrm{~g} \mathrm{q} 8 \mathrm{~h}$ & $0.27^{*}$ & & 3.48 & 124.4 & 331 & 4 & $92 \% \mathrm{~T}>\mathrm{MIC}$ & [35] \\
\hline & 17 & $2 \mathrm{~g} \mathrm{q} 8 \mathrm{~h}$ & 0.51 & $63.7^{*}$ & 6.28 & 61.65 & 523.49 & & & [34] \\
\hline & 18 & $2 \mathrm{~g} \mathrm{q} 8 \mathrm{~h}$ & 0.48 & $112^{*}$ & 5.84 & 63 & 522 & 32 & $45 \% \mathrm{~T}>4 \times \mathrm{MIC}$ & {$[20]$} \\
\hline & 10 & $2 \mathrm{~g} \mathrm{q} 8 \mathrm{~h}$ & 0.23 & $112^{*}$ & 1.98 & & & & & {$[36]$} \\
\hline & 49 & $2 \mathrm{~g}$ q8h or $6 \mathrm{~g} \mathrm{Cl} /$ day & $0.67^{*}$ & 91.3 & & & & & & [22] \\
\hline \multirow[t]{5}{*}{ Meropenem } & 8 & $2 \mathrm{~g}$ q8h or & $0.38^{*}$ & 156.7 & 2.4 & 110.1 & 193.8 & & $100 \% \mathrm{~T}>\mathrm{MIC}$ & {$[37]$} \\
\hline & 7 & $2 \mathrm{~g} \mathrm{LD}+3 \mathrm{~g} \mathrm{Cl} /$ day & $0.37^{*}$ & 128.3 & & & 117.5 & & $100 \% \mathrm{~T}>\mathrm{MIC}$ & \\
\hline & 16 & $1 \mathrm{~g} \mathrm{q} 8 \mathrm{~h}$ & 0.43 & $130.9^{*}$ & 2.05 & 35 & 132 & 8 & $57 \% \mathrm{~T}>4 \times \mathrm{MIC}$ & [20] \\
\hline & 10 & $1 \mathrm{~g}$ q8h or $3 \mathrm{~g} \mathrm{Cl} /$ day & $0.32^{*}$ & 226.7 & & & & & & {$[23]$} \\
\hline & 10 & $1 \mathrm{~g} \mathrm{q} 8 \mathrm{~h}$ & $0.39^{*}$ & 191 & 2.13 & 46.6 & 99.5 & $0.25-1$ & $100 \% \mathrm{~T}>\mathrm{MIC}$ & [38] \\
\hline \multirow[t]{3}{*}{ Piperacillin } & 8 & 12/1.5 g PIP/TAZ Cl & 0.33 & 286.7 & & 144 & & & & [24] \\
\hline & 8 & 4/0.5 PIP/TAZ q6h or q8h & & & & 266.6 & & & & \\
\hline & 27 & $4 \mathrm{~g} \mathrm{q6h}$ & 0.38 & $141.4^{*}$ & 2.58 & 123 & 469 & 64 & $33 \% \mathrm{~T}>4 \times \mathrm{MIC}$ & {$[20]$} \\
\hline \multirow[t]{2}{*}{ Ceftriaxone } & 54 & $2 \mathrm{~g} \mathrm{qd}$ & $0.28^{*}$ & 14.7 & 9.6 & & & 8 & $16 \% \mathrm{~T}>\mathrm{MIC}$ & {$[25]$} \\
\hline & 10 & $2 \mathrm{~g} \mathrm{qd}$ & $0.28^{*}$ & 41.3 & 6.4 & 204.9 & & & & {$[30]$} \\
\hline \multirow[t]{2}{*}{ Ertapenem } & 17 & $1 \mathrm{~g} \mathrm{Cl} /$ day & $0.21^{*}$ & 43.2 & 4.15 & 90 & 418 & 2 & $25 \% \mathrm{~T}>\mathrm{MIC}$ & [39] \\
\hline & 8 & $1 \mathrm{~g} \mathrm{qd}$ & $0.85^{*}$ & 200.5 & 5.7 & 94.1 & 317.7 & & & [26] \\
\hline Flucloxacillin & 10 & & $0.29^{*}$ & 150.2 & 2.45 & & & & & {$[27]$} \\
\hline
\end{tabular}

$\mathrm{Vd}$, volume of distribution; $\mathrm{CL}$, clearance; $\mathrm{C}_{\max }$, peak serum concentration; $\mathrm{AUC}$, area under the concentration vs. time curve; MIC, minimum inhibitory concentration; $\mathrm{Cl}$, continuous infusion; LD, loading dose; PIP, piperacillin; TAZ, tazobactam; *Data were converted considering $70 \mathrm{~kg}$ body weight. 
Table 2 Pharmacokinetic parameters of selected beta-lactam antibiotics in critically ill patients undergoing CRRT

Antibiotic Patients Dose Renal replacement Pharmacokinetic data

\begin{tabular}{|c|c|c|c|c|c|c|c|c|c|c|c|c|c|c|c|}
\hline & & \multicolumn{2}{|l|}{ modalities } & \multicolumn{11}{|c|}{ 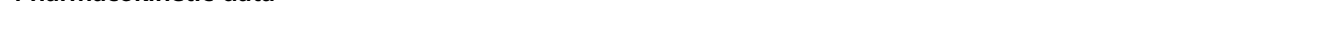 } \\
\hline & & & $\overline{\mathrm{RRT}}$ & Dialyzer & $\begin{array}{l}\mathrm{Q}_{\mathrm{B}} \\
(\mathrm{mL} / \mathrm{min})\end{array}$ & $\begin{array}{l}\mathrm{Q}_{\mathrm{UF}} \\
(\mathrm{mL} / \mathrm{min})\end{array}$ & $\begin{array}{l}\mathrm{Q}_{\mathrm{DF}} \\
(\mathrm{mL} / \mathrm{h})\end{array}$ & $\begin{array}{l}C_{\max } \\
(\mathrm{mg} / \mathrm{L})\end{array}$ & $\begin{array}{l}t_{\mathrm{H}} \\
(\mathrm{h})\end{array}$ & $\begin{array}{l}V d \\
(1 / \mathrm{kg})\end{array}$ & $\begin{array}{l}\text { AUC } \\
(\mathrm{mg} \cdot \mathrm{h} / \mathrm{L})\end{array}$ & $\begin{array}{l}\mathrm{CL}_{\text {tot }} \\
(\mathrm{mL} / \mathrm{min})\end{array}$ & $\begin{array}{l}C L_{\mathrm{RRT}} \\
\text { (mL/min) }\end{array}$ & Sc/Sa & Ref. \\
\hline \multirow[t]{4}{*}{ Cefepime } & 4 & $2 \mathrm{~g} \mathrm{q} 8 \mathrm{~h}$ & $\mathrm{CWH}$ or $\mathrm{CWHD}$ & PAN or PS & $140-250$ & $16.7-35$ & $500-1000$ & $100.5 \mid$ & 4.6 & 0.6 & & 111.5 & 27.2 & 0.76 & {$[67]$} \\
\hline & 5 & $1-4 \mathrm{~g}$ q12h or q24h & $\mathrm{CWH}$ & PAN & 150 & 16 & & $44.6-94.9$ & 12.9 & 0.46 & $834.7-1,677.8$ & 35.9 & 13 & 0.86 & {$[66]$} \\
\hline & 7 & 1-4 g q12h or q24h & CWHDF & PAN & 150 & 17 & $857-1020$ & $25.7-90.8$ & 8.6 & 0.34 & $344.9-1,306.8$ & 46.8 & 26 & 0.78 & \\
\hline & 8 & $2 \mathrm{~g} \mathrm{q} 12 \mathrm{~h}$ & $\mathrm{CWH}$ or $\mathrm{CWHDF}$ & AN69 & 150 & $25.7^{*}$ & $1610^{*}$ & 43 & 6.17 & 0.55 & 379 & $72.8^{*}$ & & & {$[84]$} \\
\hline \multirow[t]{4}{*}{ Ceftazidime } & 12 & $2 \mathrm{~g} \mathrm{q} 8 \mathrm{~h}$ & $\mathrm{CWH}$ & PS & 143 & 47 & & 58.2 & 4.3 & $0.52^{*}$ & 344 & 98.7 & 32.1 & 0.69 & {$[70]$} \\
\hline & 7 & $3 \mathrm{~g} \mathrm{q} 24 \mathrm{~h}$ & CWDHF & AN69 & 150 & 25 & 1000 & & 4 & $0.27^{*}$ & 2514 & 62 & 33.6 & 0.81 & [69] \\
\hline & 4 & $1-2 \mathrm{~g} \mathrm{q} 6 \mathrm{~h}$ & $\mathrm{CWH}$ or $\mathrm{CWHDF}$ & AN69 or PS & $130-140$ & 25 & $500-1000$ & $53.9-112$ & 6.4 & 0.67 & & $35.5-333.8$ & $5-65.6$ & 0.93 & [82] \\
\hline & 12 & $2 \mathrm{~g} \mathrm{q12h}$ & $\mathrm{CWH}$ or $\mathrm{CWHDF}$ & AN69 & 150 & $25.7^{*}$ & $1610^{*}$ & 78 & 7.74 & 0.37 & 536 & $36.4^{*}$ & & & [84] \\
\hline \multirow[t]{8}{*}{ Meropenem } & 8 & $500 \mathrm{mg}$ q12h & $\mathrm{CWH}$ & AN69 & 10 & 26.7 & & 39.5 & 3.63 & & 105.3 & 82.94 & 24.42 & 0.91 & [71] \\
\hline & 5 & $1 \mathrm{~g} \mathrm{q} 12 \mathrm{~h}$ & $\mathrm{CWH}$ & AN69 & 150 & $16.7-33.3$ & & & 5.16 & $0.39^{*}$ & 246 & 4.3 & 1.96 & 0.93 & {$[86]$} \\
\hline & 5 & $1 \mathrm{~g} \mathrm{q} 12 \mathrm{~h}$ & CWDHF & AN69 & 150 & $16.7-25$ & $1000-1500$ & & & & & & & & \\
\hline & 10 & $1 \mathrm{~g} \mathrm{q} 8 \mathrm{~h}$ & High volume CWH & AN69 & 250 & $66.7-100$ & & 56.6 & 4.3 & 0.2 & 166.5 & 100 & 58.3 & 0.93 & [72] \\
\hline & 15 & $0.5-1 \mathrm{~g}$ q8h or q12h & CWHDF & AN 69 & $90-150$ & $0.17-4.5$ & $600-1500$ & & 5.1 & $0.47^{*}$ & & 75 & 26.7 & 0.65 & {$[87]$} \\
\hline & 5 & $0.5 \mathrm{~g} \mathrm{q} 12 \mathrm{~h}$ & $\mathrm{CWH}$ & PAN & 200 & $25-30$ & & 24.5 & 6.37 & 0.37 & 129.5 & 4.57 & 1.03 & 0.63 & {$[88]$} \\
\hline & 9 & $0.5 \mathrm{~g}$ q8h or q12h & $\mathrm{CWH}$ & AN69 & $150-170$ & $1.7-2.5$ & & 38.9 & 8.7 & $0.17^{*}$ & & 52 & 22 & 1.17 & {$[72]$} \\
\hline & 9 & $1 \mathrm{~g} \mathrm{Stat}$ & $\mathrm{CWH}$ & PS & 150 & 45.8 & & 28.1 & & $0.37^{*}$ & 118 & 143.7 & 49.7 & 0.24 & {$[89]$} \\
\hline \multirow{4}{*}{$\begin{array}{l}\text { Piperacillin/ } \\
\text { tazobactam }\end{array}$} & \multirow[t]{3}{*}{6} & \multirow[t]{3}{*}{$4 \mathrm{~g} \mathrm{q} 12 \mathrm{~h} / 0.5 \mathrm{~g} \mathrm{q} 12 \mathrm{~h}$} & $\mathrm{CWH}$ & PS & \multirow[t]{3}{*}{100} & \multirow[t]{3}{*}{13.3} & & & \multicolumn{2}{|l|}{$7.7 / 13.9$} & & \multicolumn{2}{|l|}{$64.8 / 40.3$} & & \multirow[t]{3}{*}[90]{} \\
\hline & & & \multirow{2}{*}{\multicolumn{2}{|c|}{ CWHDF }} & & & 1000 & & $6.7 / 11.6$ & & & $84.3 / 52.2$ & & & \\
\hline & & & & & & & 2000 & & $6.1 / 9.4$ & & & $91.3 / 62.5$ & & & \\
\hline & 8 & $2 \mathrm{~g} / 0.25 \mathrm{~g}$ or $4 \mathrm{~g} / 0.5 \mathrm{~g}$ & CWHD & AN69 & 150 & $1.3-3.3$ & 1500 & & $4.3 / 5.6$ & $0.31 / 0.24$ & & $47 / 29.5$ & $22 / 17$ & $0.87 / 0.64$ & [91] \\
\hline Ceftriaxone & 6 & $2-4 \mathrm{~g}$ q24h & $\mathrm{CWH}$ & PA & $100-150$ & $20-30$ & & & 10.8 & $0.45^{*}$ & & & 16.6 & 0.69 & {$[77]$} \\
\hline Flucloxacillin & 10 & $4 \mathrm{~g} \mathrm{q} 8 \mathrm{~h}$ & CWH & PA & 169 & 57 & & 139.1-179.7 & 4.9 & $0.69^{*}$ & 568 & 117.2 & & 0.21 & [79] \\
\hline
\end{tabular}

$\mathrm{Q}_{\mathrm{B}}$, blood flow rate; $\mathrm{Q}_{\mathrm{UF}}$ ultrafiltration rate; $\mathrm{Q}_{\mathrm{DF}}$, dialysate flow rate; RRT, renal replacement therapy; Sc, sieving coefficient; $\mathrm{Sa}$, saturation coefficient; $\mathrm{Vd}$, volume of distribution; $\mathrm{CL}$, clearance; $\mathrm{C}_{\text {max, }}$ peak serum concentration; $t_{H}$, half-life; AUC, area under the concentration vs time curve; $\mathrm{CVVH}$, continuous venovenous hemofiltration; CVVHD, continuous venovenous hemodialysis; $C V V H D F$, continuous venovenous hemodiafiltration; PAN, polyacrylonitrile; PS, polysulfone; PA, polyamide; *Data were converted considering 70 kg body weight. 


$\begin{aligned} & \text { Table } 3 \text { Characteristics of drugs traditionally considered } \\
& \text { to require TDM }[\mathbf{9 2 , 9 3 ]}\end{aligned}$
\begin{tabular}{ll} 
No. & Criteria \\
\hline 1 & Narrow therapeutic range/index \\
\hline 2 & $\begin{array}{l}\text { Drug toxicity may lead to hospitalization, } \\
\text { irreversible organ damage, and even death }\end{array}$ \\
\hline 3 & $\begin{array}{l}\text { No clearly defined clinical parameter that } \\
\text { allows dose adjustments }\end{array}$ \\
\hline 4 & $\begin{array}{l}\text { Correlation exists between serum concentration } \\
\text { and efficacy as well as toxicity }\end{array}$ \\
\hline 5 & $\begin{array}{l}\text { Unpredictable relationship between dose and } \\
\text { clinical outcome }\end{array}$ \\
\hline 6 & $\begin{array}{l}\text { Difficult to predict pharmacokinetics } \\
\text { (e.g. non-linear pharmacokinetics) }\end{array}$ \\
\hline
\end{tabular}

on the prevention of drug toxicity. For many drugs that fulfill the first of these criteria, a narrow therapeutic index (e.g., aminoglycosides), TDM is commonly performed. For drugs with a wider therapeutic index, including beta-lactams, TDM has previously been considered to be less clinically relevant because of a lower risk of toxicity. However, TDM may be used, not only to minimize toxicity but also to maximize efficacy [92]. In fact, the primary goal of TDM may be to optimize the clinical response to treatment, with a secondary goal being avoidance of adverse effects.

Further rationale for measuring therapeutic betalactam concentrations relates to the absence of a "clearly defined clinical parameter that allows dose adjustments" (criterion 3). For conventional drugs that are subjected to TDM, such as aminoglycosides, it is difficult to monitor toxicity clinically unless drug levels are monitored, because endpoints for toxicity are poorly defined [92]. Similarly, for beta-lactam antibiotic therapy, there is no established or uniform clinical endpoint that reliably describes resolution of infection and, therefore, adequate dosing. Confirmation of dosing appropriateness using antibiotic concentrations is therefore potentially useful.

The "relationship between dose and clinical outcome" for beta-lactams also is unpredictable (criterion 5) due to the variability in clinical response both between and within patients from one dose to the next. A beta-lactam dose that produces a therapeutic effect in one patient may produce toxicity or no clinical response in another patient most probably because of differences in drug distribution into different physiological compartments. Although the PK of beta-lactams in the noncritically ill is generally predictable, the rapidly changing acute pathophysiology and organ dysfunction that occurs in the critically ill means that any assumptions about drug concentrations are unreliable and dose-effect relationships are unpredictable.

Finally, even though "non-linear PK" (criterion 6) is not common for beta-lactams, drug accumulation and toxicity can occur due to renal impairment. For example, the accumulation of cefepime in critically ill patients with acute renal failure has been reported to lead to neurotoxicity [63-65,94]. Furthermore, attempts to prevent such toxicity by using standard dose adjustment algorithms [49] have been shown to be unsuccessful. For piperacillin also, similar toxicities have been reported in advanced renal failure at doses conventionally recommended for patients with renal impairment $[95,96]$. Compressive reviews of neurotoxicity by beta-lactam antibiotics have been published [85,94,97] and emphasize the need for vigilant monitoring.

\section{Studies assessing beta-lactam TDM in a clinical environment}

Although TDM of beta-lactam antibiotics in the critically ill patient population has previously been called for $[27,34,49,91,98]$, to date, only a few studies describing its utility have been performed [16,45,99-102]. Roberts et al. prospectively evaluated TDM in 236 ICU patients and reported that beta-lactam dose adjustment was necessary for $74.2 \%$ of patients; $50.4 \%$ of the total patients required a dose increment after the first measurement. Their limited outcome findings indicate success rate of $87.3 \%$ antibiotic course completion. More recently, the clinical utility of beta-lactam TDM was prospectively examined in a cohort of 50 burn injury patients in a ward environment. For $60 \%$ of patients, trough concentrations were less than the target MIC and dose adjustment was required. For patients achieving therapeutic targets, a statistically significant shorter duration of antibiotic therapy was described, thereby demonstrating the therapeutic utility of a TDM program [103].

A prospective study by Aubert et al. [45] assessed serum ceftazidime concentrations in 92 ICU patients. The authors reported that $37 \%$ of patients had inadequate ceftazidime concentrations and $27 \%$ had excessive concentrations. Ceftazidime dosage was adjusted accordingly to ensure therapeutic concentrations. Connor et al. [104] reported a novel approach for measuring piperacillin-tazobactam drug levels in patients receiving continuous veno-venous hemodialysis (CVVHD) whereby CVVHD effluent was assayed to provide an estimation of plasma drug concentrations for TDM. A piperacillin TDM program in ICU patients using plasma drug concentrations also has been evaluated by Blondiaux et al. [100]. The authors reported that $50 \%$ of patients had plasma piperacillin concentrations within the therapeutic target range after continuous infusion of the initial dose and before TDM. Subsequent TDMguided dose adjustment increased this proportion to $75 \%$.

For meropenem, Taccone et al.[102] recently demonstrated that TDM-guided dose optimization resulted in a 
successful resolution of sepsis in a patient with extensively drug-resistant Pseudomonas aeruginosa. Interestingly, the study demonstrates a rapid emergence of extensively resistant strains most probably due to subinhibitory exposure arising from commonly used dose of $1 \mathrm{~g}$ q8h followed by $2 \mathrm{~g}$ q8h (MIC was $2 \mathrm{mg} / \mathrm{L}$ on day 1 , $4 \mathrm{mg} / \mathrm{L}$ on day 6 , and $8 \mathrm{mg} / \mathrm{L}$ a few days later). The investigators performed TDM less frequently (initially on days 2 and 5 of treatment) and were not able to adjust doses early enough to prevent the emergence of resistance and/or therapeutic failure. Their observation, however, presents a novel evidence to suggest frequent TDM: perhaps daily and certainly in the earlier phase of treatment. A case report by Pea et al. [101] also described an intensive TDM process for meropenem and daptomycin.

In summary, the available evidence supporting a beneficial role for beta-lactam TDM in the critically ill is limited. The benefits of TDM may be most evident in patients with severe sepsis as well as in infections with organisms having high MIC. Whether or not TDMdriven dose optimization results in improved clinical outcomes, awaits evidence from a randomized, controlled, clinical trial. It also should be noted that the specified PK/PD target has varied between studies performed to date and to ensure the maximal benefit of TDM an understanding of the appropriate PK/PD targets is essential.

\section{Is there a defined PD target for beta-lactam TDM?}

For beta-lactams, the best index that describes efficacy is the time the free drug concentration remains above MIC $\left(f \mathrm{~T}_{>\text {MIC }}\right)$ [105]. However, the optimal $f \mathrm{~T}_{>\text {MIC }}$ is controversial.

Animal studies suggest that maximal effects can be achieved when $f \mathrm{~T}_{>\mathrm{MIC}}$ is less than $100 \%$ of the dosing interval, depending on the antibiotic and the organism targeted $[51,53,105]$. In several studies of cephalosporins, 60-70\% $f \mathrm{~T}_{>\mathrm{MIC}}$ against Enterobacteriaceae and 40-50\% $f \mathrm{~T}_{>\mathrm{MIC}}$ against Staphylococcus aureus have been reported to produce maximal effect [105]. Earlier animal studies also have indicated that Staphylococci have maximum killing at $50-60 \% f \mathrm{~T}_{>\text {MIC }}$, whereas $90-100 \%$ $f \mathrm{~T}_{>\mathrm{MIC}}$ are required for Gram-negative Bacilli and Streptococci, presumably due to the absence of a postantibiotic effect $[51,53]$. For carbapenems, which have relatively high postantibiotic effect, bacteriostatic activity is achieved at $20 \% f \mathrm{~T}_{>\text {MIC }}$ and bactericidal effects are observed at $40 \% f \mathrm{~T}_{>\text {MIC }}[106]$.

Mouton et al. [107] reported in a dynamic in vitro model that maintaining ceftazidime concentration around or slightly above the MIC is not sufficient enough to ensure prolonged efficacy and that targeting $f \mathrm{~T}_{>4 \mathrm{xMIC}}$ provided sustained and better effect. For meropenem, beneficial outcomes have been observed when the target $f \mathrm{~T}_{>4-5 x M I C}$ is maintained [73]. Finally, Tam et al. [108] reported that exposure to $6 x M I C$ is necessary for meropenem to suppress resistance emergence against $P$. aeruginosa.

In patients, TDM using either $100 \% f \mathrm{~T}_{>\mathrm{MIC}}$ [103] or $100 \% f \mathrm{~T}_{>4-5 x M I C}[45,99,100,102,103]$ for several betalactams has previously been reported. More recently, $54 \% f \mathrm{~T}_{>\text {MIC }}$ for meropenem has been reported as significant predictor of response in patients with pneumonia [5]. This, and similar studies [7,102,109], suggest that a higher duration of beta-lactam exposure may be required for optimal clinical outcomes than that reported in animal studies. Indeed, this higher exposure may relate to impaired distribution of antibiotic into ISF meaning that a higher plasma exposure is required to achieve an ISF exposure that is equivalent to the animal in vivo targets.

Given that many factors can affect the likelihood of a positive outcome in the critically ill, beta-lactam treatment should aim to attain the maximum exposure [79]. Targeting trough concentration (4-5xMIC) may decrease the likelihood of suboptimal plasma concentrations. The higher concentration would enable enhanced distribution of drug into tissues with deranged microcirculation (e.g., septic shock) and improve impaired tissue betalactam penetration $[11,61,62]$. In the absence of wellconducted, prospective, clinical trials addressing the therapeutic benefit of currently recommended PD targets, $100 \% f \mathrm{~T}_{>\text {MIC }}$ could be considered a prudent $\mathrm{PD}$ target for beta-lactams in the critically ill; albeit noncritically ill patients may only require minimal exposures of $40-70 \% f \mathrm{~T}_{>\mathrm{MIC}}$.

\section{Predicting MIC for TDM}

The MIC of a target organism(s) is usually not available upon initiation of therapy and may not become available for 24-72 hours after specimens have been sent to a microbiology laboratory. For this reason, epidemiological data of MICs for pathogens can be useful, although there may be considerable variability in the susceptibility of organisms between different institutions within the same geographic location. In cases when the causative organism has been isolated, MIC for the TDM target could be determined by in vitro tests, such as the E-test [102]. If these data are not available, an antibiogram for the local institution should be used. Alternatively national guidelines, such as that produced by The French Microbiology Society's Antibiotics Committee [100], or other databases, such as The European Committee on Antimicrobial Susceptibility Testing (EUCAST), may be highly useful $[45,99,101,103]$.

In cases in which no organisms are isolated, the susceptibility break point of the least susceptible potential 
pathogen should be used $[99,103]$. For example, if $P$. aeruginosa and $K$. pneumoniae are the most common causes of pneumonias in an ICU, and piperacillin/ tazobactam is the preferred empiric therapy, the TDM that targets the $P$. aeruginosa MIC $(16 \mathrm{mg} / \mathrm{L} P$. aeruginosa vs. $8 \mathrm{mg} / \mathrm{L}$ K. pneumoniae) would be appropriate. Later, dose adjustment could be based on the identified pathogen and associated MIC.

\section{Beta-lactam assay for use in a TDM program}

High performance liquid chromatography (HPLC) is the most common assay technique used in studies of betalactam TDM [16,45,99-102]. Verdier et al. [110] developed an HPLC assay method specifically targeting the needs of routine TDM application, thus enabling simultaneous determination of 12 beta-lactams within 22 minutes. Another robust HPLC method described by McWhinney et al. [111] analyzed 12 antibiotics simultaneously within a 7-minute run time. HPLC is, however, a relatively slow technique that requires extensive sample preparation and clean-up processes and, thus, is not suitable for urgent assay needs [112,113]. The relative cost and requirement of specialized instrumentation also is another drawback compared with other techniques, such as immunochemical assays, which use cheaper, portable, and easy-to-use instrumentations [114]. Immunochemical assays have been used for other antibiotics for which routine TDM is well established, such as aminoglycosides and vancomycin $[115,116]$. However, the development of such techniques for beta-lactams has been a challenge $[117,118]$. To date, no technique allows simple and rapid determination of unbound beta-lactam plasma concentration, which is ideally required for TDM.

\section{Conclusions}

There is enormous PK variability of beta-lactam antibiotics in critically ill patients. The majority of evidence suggests that empiric approaches to antibiotic dosing may result in subtherapeutic antibiotic concentrations and treatment failure or the emergence of antibiotic resistance. The available studies also strongly support the need for individualized dose optimization in the critically ill, which supports the need for TDM. Despite the theoretical advantages, there remains no consistent use of agreed PK/PD targets. Furthermore, none of the studies have defined the impact of TDM on clinical outcome.

\footnotetext{
Abbreviations

ARC: augmented renal clearance; CRRT: continuous renal replacement therapy; CWHD: continuous veno-venous hemodialysis; $f T_{>M I c}$ : time the free drug concentration is greater than $\mathrm{MIC} ; \mathrm{T}_{>4 \times \mathrm{MI}}$ : time the free drug concentration is greater than four times MIC; $f T_{>4-5 \times M I C}$ time the free drug concentration is greater than four to five times MIC; ISF: interstitial fluid; MIC: minimum inhibitory concentration; PD: pharmacodynamic PK: pharmacokinetic; PK/PD: pharmacokinetics and pharmacodynamics; TDM: therapeutic drug monitoring.
}

Competing interests

All authors declare that they have no competing interests.

\section{Authors' contributions}

All authors contributed to drafting of the manuscript and approved the final version.

\section{Author details}

${ }^{1}$ School of Pharmacy and Medical Sciences, University of South Australia, Adelaide, Australia. ${ }^{2}$ Therapeutics Research Centre, Basil Hetzel Institute for Translational Health Research, The Queen Elizabeth Hospital, Adelaide, Australia. ${ }^{3}$ Therapeutics Research Centre, School of Medicine, The University of Queensland, Brisbane, Australia. ${ }^{4}$ Department of Intensive Care Medicine, The Queen Elizabeth Hospital, Adelaide, Australia. ${ }^{5}$ Burns, Trauma, and Critical Care Research Centre, The University of Queensland, Herston, Brisbane, QLD, Australia. ${ }^{6}$ Department of Intensive Care Medicine, Royal Brisbane and Women's Hospital, Herston, Brisbane, QLD, Australia. ${ }^{7}$ Pharmacy Department, Royal Brisbane and Women's Hospital, Herston, Brisbane, QLD, Australia.

Received: 7 June 2012 Accepted: 28 June 2012

Published: 28 July 2012

\section{References}

1. Roberts JA, Norris R, Paterson DL, Martin JH: Therapeutic drug monitoring of antimicrobials. Br J Clin Pharmacol 2012, 73:27-36.

2. van Lent-Evers NA, Mathot RA, Geus WP, van Hout BA, Vinks AA: Impact of goal-oriented and model-based clinical pharmacokinetic dosing of aminoglycosides on clinical outcome: a cost-effectiveness analysis. Ther Drug Monit 1999, 21:63-73.

3. Moise-Broder PA, Forrest A, Birmingham MC, Schentag JJ: Pharmacodynamics of vancomycin and other antimicrobials in patients with Staphylococcus aureus lower respiratory tract infections. Clin Pharmacokinet 2004, 43:925-942.

4. Ariano RE, Nyhlen A, Donnelly JP, Sitar DS, Harding GK, Zelenitsky SA: Pharmacokinetics and pharmacodynamics of meropenem in febrile neutropenic patients with bacteremia. Ann Pharmacother 2005, 39:32-38.

5. Li C, Du X, Kuti JL, Nicolau DP: Clinical pharmacodynamics of meropenem in patients with lower respiratory tract infections. Antimicrob Agents Chemother 2007, 51:1725-1730.

6. Lodise TP Jr, Lomaestro B, Drusano GL: Piperacillin-tazobactam for Pseudomonas aeruginosa infection: clinical implications of an extendedinfusion dosing strategy. Clin Infect Dis 2007, 44:357-363.

7. McKinnon PS, Paladino JA, Schentag JJ: Evaluation of area under the inhibitory curve (AUIC) and time above the minimum inhibitory concentration ( $\mathrm{T}>\mathrm{MIC}$ ) as predictors of outcome for cefepime and ceftazidime in serious bacterial infections. Int J Antimicrob Ag 2008, 31:345-351.

8. Niemiec PW Jr, Allo MD, Miller CF: Effect of altered volume of distribution on aminoglycoside levels in patients in surgical intensive care. Arch Surg 1987, 122:207-212

9. Dorman T, Swoboda S, Zarfeshenfard F, Trentler B, Lipsett PA: Impact of altered aminoglycoside volume of distribution on the adequacy of a three milligram per kilogram loading dose. Critical Care Research Group. Surgery 1998, 124:73-78.

10. Roos JF, Lipman J, Kirkpatrick CM: Population pharmacokinetics and pharmacodynamics of cefpirome in critically ill patients against Gramnegative bacteria. Intensive Care Med 2007, 33:781-788.

11. Joukhadar C, Frossard M, Mayer BX, Brunner M, Klein N, Siostrzonek P, Eichler HG, Muller M: Impaired target site penetration of beta-lactams may account for therapeutic failure in patients with septic shock. Crit Care Med 2001, 29:385-391.

12. Erlandsson M, Burman LG, Cars O, Gill H, Nilsson LE, Walther SM, Hanberger $\mathrm{H}$ : Prescription of antibiotic agents in Swedish intensive care units is empiric and precise. Scand J Infect Dis 2007, 39:63-69.

13. Roberts JA: Using PK/PD to optimize antibiotic dosing for critically ill patients. Curr Pharmaceut Biotechnol 2011, 12:2070-2079.

14. Mohr JF, Wanger A, Rex JH: Pharmacokinetic/pharmacodynamic modeling can help guide targeted antimicrobial therapy for nosocomial gramnegative infections in critically ill patients. Diagn Micr Infec Dis 2004, 48:125-130. 
15. Goncalves-Pereira J, Povoa P: Antibiotics in critically ill patients - a systematic review of the pharmacokinetics of beta-Lactams. Crit Care 2011, 15:R206.

16. Scaglione F: Can PK/PD be used in everyday clinical practice. Int $J$ Antimicrob Ag 2002, 19:349-353.

17. Roberts JA, Hope WW, Lipman J: Therapeutic drug monitoring of betalactams for critically ill patients: unwarranted or essential? Int J Antimicrob Agents 2010, 35:419-420.

18. Lipman J, Wallis SC, Boots RJ: Cefepime versus cefpirome: the importance of creatinine clearance. Anesth Analg 2003, 97:1149-1154.

19. Kieft H, Hoepelman Al, Knupp CA, van Dijk A, Branger JM, Struyvenberg A, Verhoef J: Pharmacokinetics of cefepime in patients with the sepsis syndrome. J Antimicrob Chemother 1993, 32(Suppl B):117-122

20. Taccone FS, Laterre P-F, Dugernier T, Spapen H, Delattre I, Wittebole X, De Backer D, Layeux B, Wallemacq P, Vincent J-L, Jacobs F: Insufficient betalactam concentrations in the early phase of severe sepsis and septic shock. Crit Care 2010, 14:R126.

21. Gomez CM, Cordingly JJ, Palazzo MG: Altered pharmacokinetics of ceftazidime in critically ill patients. Antimicrob Agents Chemother 1999, 43:1798-1802.

22. Georges B, Conil J-M, Seguin T, Ruiz S, Minville V, Cougot P, Decun J-F, Gonzalez H, Houin G, Fourcade O, Saivin S: Population pharmacokinetics of ceftazidime in intensive care unit patients: influence of glomerular filtration rate, mechanical ventilation, and reason for admission. Antimicrob Agents Chemother 2009, 53:4483-4489.

23. Douglas A, Udy AA, Wallis SC, Jarrett $P$, Stuart J, Lassig-Smith M, Deans $R$, Roberts MS, Taraporewalla K, Jenkins J, Medley G, Lipman J, Roberts JA: Plasma and tissue pharmacokinetics of cefazolin in patients undergoing elective and semi-elective abdominal aortic aneurysm open repair surgery. Antimicrob Agents Chemother 2011, 55:5238-5242.

24. Roberts JA, Kirkpatrick CMJ, Roberts MS, Dalley AJ, Lipman J: First-dose and steady-state population pharmacokinetics and pharmacodynamics of piperacillin by continuous or intermittent dosing in critically ill patients with sepsis. Int J Antimicrob Ag 2010, 35:156-163.

25. Garot D, Respaud R, Lanotte P, Simon N, Mercier E, Ehrmann S, Perrotin D, Dequin PF, Le Guellec C: Population pharmacokinetics of ceftriaxone in critically ill septic patients: a reappraisal. Br J Clin Pharmacol 2011, 72:758-767.

26. Brink AJ, Richards GA, Schillack V, Kiem S, Schentag J: Pharmacokinetics of once-daily dosing of ertapenem in critically ill patients with severe sepsis. Int J Antimicrob Ag 2009, 33:432-436.

27. Ulldemolins M, Roberts JA, Wallis SC, Rello J, Lipman J: Flucloxacillin dosing in critically ill patients with hypoalbuminaemia: special emphasis on unbound pharmacokinetics. J Antimicrob Chemother 2010, 65:1771-1778.

28. Van Dalen $R$, Vree TB, Baars IM: Influence of protein binding and severity of illness on renal elimination of four cephalosporin drugs in intensivecare patients. Pharm Weekb/ Sci 1987, 9:98-103.

29. Moon YS, Chung KC, Gill MA: Pharmacokinetics of meropenem in animals, healthy volunteers, and patients. Clin Infect Dis 1997. 24(Suppl 2):S249-S255.

30. Joynt GM, Lipman J, Gomersall CD, Young RJ, Wong EL, Gin T: The pharmacokinetics of once-daily dosing of ceftriaxone in critically ill patients. J Antimicrob Chemother 2001, 47:421-429.

31. Udy AA, Putt MT, Shanmugathasan S, Roberts JA, Lipman J: Augmented renal clearance in the Intensive Care Unit: an illustrative case series. Int J Antimicrob Ag 2010, 35:606-608.

32. Burkhardt O, Kumar V, Katterwe D, Majcher-Peszynska J, Drewelow B, Derendorf $\mathrm{H}$, Welte $\mathrm{T}$ : Ertapenem in critically ill patients with early-onset ventilator-associated pneumonia: pharmacokinetics with special consideration of free-drug concentration. J Antimicrob Chemother 2007 59:277-284

33. Lipman J, Wallis SC, Rickard C: Low plasma cefepime levels in critically ill septic patients: pharmacokinetic modeling indicates improved troughs with revised dosing. Antimicrob Agents Chemother 1999, 43:2559-2561.

34. Delattre IK, Musuamba FT, Verbeeck RK, Dugernier T, Spapen H, Laterre P-F, Wittebole X, Cumps J, Taccone FS, Vincent J-L, Jacobs F, Wallemacq PE: Empirical models for dosage optimization of four beta-lactams in critically ill septic patients based on therapeutic drug monitoring of amikacin. Clin Biochem 2010, 43:589-598.

35. Benko AS, Cappelletty DM, Kruse JA, Rybak MJ: Continuous infusion versus intermittent administration of ceftazidime in critically ill patients with suspected gram-negative infections. Antimicrob Agents Chemother 1996, 40:691-695.

36. Young RJ, Lipman J, Gin T, Gomersall CD, Joynt GM, Oh TE: Intermittent bolus dosing of ceftazidime in critically ill patients. J Antimicrob Chemother 1997, 40:269-273.

37. Thalhammer F, Traunmuller F, El Menyawi I, Frass M, Hollenstein UM, Locker GJ, Stoiser B, Staudinger T, Thalhammer-Scherrer R, Burgmann H: Continuous infusion versus intermittent administration of meropenem in critically ill patients. J Antimicrob Chemother 1999, 43:523-527.

38. Novelli A, Adembri C, Livi P, Fallani S, Mazzei T, De Gaudio AR: Pharmacokinetic evaluation of meropenem and imipenem in critically ill patients with sepsis. Clin Pharmacokinet 2005, 44:539-549.

39. Burkhardt O, Derendorf H, Welte T: Ertapenem: the new carbapenem 5 years after first FDA licensing for clinical practice. Expert Opin Pharmacother 2007, 8:237-256.

40. Boselli E, Breilh D, Saux M-C, Gordien J-B, Allaouchiche B: Pharmacokinetics and lung concentrations of ertapenem in patients with ventilatorassociated pneumonia. Intens Care Med 2006, 32:2059-2062.

41. Burgess DS, Frei CR: Comparison of beta-lactam regimens for the treatment of gram-negative pulmonary infections in the intensive care unit based on pharmacokinetics/pharmacodynamics. J Antimicrob Chemother 2005, 56:893-898.

42. Tam VH, Louie A, Lomaestro BM, Drusano GL: Integration of population pharmacokinetics, a pharmacodynamic target, and microbiologic surveillance data to generate a rational empiric dosing strategy for cefepime against Pseudomonas aeruginosa. Pharmacotherapy 2003, 23:291-295.

43. DeRyke CA, Kuti $\lrcorner$, Nicolau DP: Pharmacodynamic target attainment of six beta-lactams and two fluoroquinolones against Pseudomonas aeruginosa, Acinetobacter baumannii, Escherichia coli, and Klebsiella species collected from United States intensive care units in 2004 Pharmacotherapy 2007, 27:333-342.

44. Zelenitsky SA, Ariano RE, Zhanel GG: Pharmacodynamics of empirical antibiotic monotherapies for an intensive care unit (ICU) population based on Canadian surveillance data. J Antimicrob Chemother 2011, 66:343-349.

45. Aubert G, Carricajo A, Coudrot M, Guyomarc'h S, Auboyer C, Zeni F: Prospective determination of serum ceftazidime concentrations in intensive care units. Ther Drug Monit 2010, 32:517-519.

46. Hallam MJ, Allen JM, James SE, Donaldson PMW, Davies JG, Hanlon GW, Dheansa BS: Potential subtherapeutic linezolid and meropenem antibiotic concentrations in a patient with severe burns and sepsis. $J$ Burn Care Res 2010, 31:207-209.

47. Burkhardt O, Kumar V, Schmidt S, Kielstein JT, Welte T, Derendorf H: Underdosing of ertapenem in critically ill patients with pneumonia confirmed by Monte Carlo simulations. Int J Antimicrob Agents 2010, 35:96-97.

48. Boyadjiev I, Boulamery A, Simon N, Martin C, Bruguerolle B, Leone M: Penetration of Ertapenem into Muscle Measured by In Vivo Microdialysis in Mechanically Ventilated Patients. Antimicrob Agents Ch 2011, 55:3573-3575.

49. Chapuis TM, Giannoni E, Majcherczyk PA, Chiolero R, Schaller M-D, Berger MM, Bolay S, Decosterd LA, Bugnon D, Moreillon P: Prospective monitoring of cefepime in intensive care unit adult patients. Crit Care 2010, 14:R51.

50. Kiffer CRV, Kuti JL, Mendes CMF, Oplustil CP, Amarante JB, Biancalana ML Xavier N, Nicolau DP: A pharmacodynamic strategy to optimize empirical antibiotic therapy for gram-negative bacteria in a Brazilian Intensive Care Unit. Braz J Infect Dis 2007, 11:183-185.

51. Craig WA: Pharmacokinetic/pharmacodynamic parameters: rationale for antibacterial dosing of mice and men. Clin Infect Dis 1998 26:1-10. quiz 11-12.

52. Vogelman B, Gudmundsson S, Leggett J, Turnidge J, Ebert S, Craig WA Correlation of Antimicrobial Pharmacokinetic Parameters with Therapeutic Efficacy in an Animal Model. J Infect Dis 1988, 158:831-847.

53. Turnidge JD: The pharmacodynamics of beta-lactams. Clin Infect Dis 1998, 27:10-22.

54. Alou L, Aguilar L, Sevillano D, Gimenez M-J, Echeverria O, Gomez-Lus M-L, Prieto J: Is there a pharmacodynamic need for the use of continuous versus intermittent infusion with ceftazidime against Pseudomonas aeruginosa? An in vitro pharmacodynamic model. J Antimicrob Chemother 2005, 55:209-213. 
55. Buijk SLCE, Gyssens IC, Mouton JW, Van Vliet A, Verbrugh HA, Bruining HA: Pharmacokinetics of ceftazidime in serum and peritoneal exudate during continuous versus intermittent administration to patients with severe intra-abdominal infections. J Antimicrob Chemother 2002, 49:121-128.

56. Lipman J, Gomersall CD, Gin T, Joynt GM, Young RJ: Continuous infusion ceftazidime in intensive care: a randomized controlled trial. $J$ Antimicrob Chemother 1999, 43:309-311.

57. Nicolau DP, Lacy MK, McNabb JC, Quintiliani R, Nightingale $\mathrm{CH}$ : Pharmacokinetics of continuous and intermittent ceftazidime in intensive care unit patients with nosocomial pneumonia. Infect Dis Clin Prac 1999, 8:45-49.

58. Nicolau DP, McNabb J, Lacy MK, Quintiliani R, Nightingale CH: Continuous versus intermittent administration of ceftazidime in intensive care unit patients with nosocomial pneumonia. Int J Antimicrob Ag 2001, 17:497-504.

59. Nicolau DP, McNabb JC, Lacy MK, Li J, Quintiliani R, Nightingale CH: Pharmacokinetics and pharmacodynamics of continuous and intermittent ceftazidime during the treatment of nosocomial pneumonia. Clin Drug Invest 1999, 18:133-139.

60. Roberts JA, Webb S, Paterson D, Ho KM, Lipman J: A systematic review on clinical benefits of continuous administration of beta-lactam antibiotics. Crit Care Med 2009, 37:2071-2078.

61. Roberts JA, Roberts MS, Robertson TA, Dalley AJ, Lipman J: Piperacillin penetration into tissue of critically ill patients with sepsis-bolus versus continuous administration? Crit Care Med 2009, 37:926-933.

62. Roberts JA, Kirkpatrick CMJ, Roberts MS, Robertson TA, Dalley AJ, Lipman J: Meropenem dosing in critically ill patients with sepsis and without renal dysfunction: intermittent bolus versus continuous administration? Monte Carlo dosing simulations and subcutaneous tissue distribution. $J$ Antimicrob Chemother 2009, 64:142-150.

63. Abanades S, Nolla J, Rodriguez-Campello A, Pedro C, Valls A, Farre M: Reversible coma secondary to cefepime neurotoxicity. Ann Pharmacother 2004, 38:606-608.

64. Bresson J, Paugam-Burtz C, Josserand J, Bardin C, Mantz J, Pease S: Cefepime overdosage with neurotoxicity recovered by high-volume haemofiltration. J Antimicrob Chemother 2008, 62:849-850.

65. Dakdouki GK, Al-Awar GN: Cefepime-induced encephalopathy. Int J Infect Dis 2004, 8:59-61.

66. Malone RS, Fish DN, Abraham E, Teitelbaum I: Pharmacokinetics of cefepime during continuous renal replacement therapy in critically ill patients. Antimicrob Agents Chemother 2001, 45:3148-3155.

67. Isla A, Gascon AR, Maynar J, Arzuaga A, Toral D, Pedraz JL: Cefepime and continuous renal replacement therapy (CRRT): in vitro permeability of two CRRT membranes and pharmacokinetics in four critically ill patients. Clin Ther 2005, 27:599-608.

68. Allaouchiche B, Breilh D, Jaumain H, Gaillard B, Renard S, Saux MC Pharmacokinetics of cefepime during continuous venovenous hemodiafiltration. Antimicrob Agents Chemother 1997, 41:2424-2427.

69. Mariat C, Venet C, Jehl F, Mwewa S, Lazarevic V, Diconne E, Fonsale N, Carricajo A, Guyomarc'h S, Vermesch R, Aubert G, Bidault R, Bertrand J-C, Zeni F: Continuous infusion of ceftazidime in critically ill patients undergoing continuous venovenous haemodiafiltration: pharmacokinetic evaluation and dose recommendation. Crit Care 2006, 10:R26.

70. Traunmuller F, Schenk P, Mittermeyer C, Thalhammer-Scherrer R, Ratheiser K, Thalhammer $F$ : Clearance of ceftazidime during continuous venovenous haemofiltration in critically ill patients. J Antimicrob Chemother 2002, 49:129-134.

71. Krueger WA, Neeser G, Schuster H, Schroeder TH, Hoffmann E, Heininger A Dieterich $\mathrm{H}-\mathrm{J}$, Forst $\mathrm{H}$, Unertl KE: Correlation of meropenem plasma levels with pharmacodynamic requirements in critically ill patients receiving continuous veno-venous hemofiltration. Chemotherapy 2003, 49:280-286.

72. Tegeder I, Neumann F, Bremer F, Brune K, Lotsch J, Geisslinger G: Pharmacokinetics of meropenem in critically ill patients with acute renal failure undergoing continuous venovenous hemofiltration. Clin Pharmacol Ther 1999, 65:50-57.

73. Bilgrami I, Roberts JA, Wallis SC, Thomas J, Davis J, Fowler S, Goldrick PB, Lipman J: Meropenem dosing in critically ill patients with sepsis receiving high-volume continuous venovenous hemofiltration. Antimicrob Agents Chemother 2010, 54:2974-2978.

74. Keller E, Bohler J, Busse-Grawitz A, Reetze-Bonorden P, Krumme B, Schollmeyer $P$ : Single dose kinetics of piperacillin during continuous arteriovenous hemodialysis in intensive care patients. Clin Nephrol 1995, 43(Suppl 1):S20-S23.

75. Arzuaga A, Maynar J, Gascon AR, Isla A, Corral E, Fonseca F, SanchezIzquierdo JA, Rello J, Canut A, Pedraz JL: Influence of renal function on the pharmacokinetics of piperacillin/tazobactam in intensive care unit patients during continuous venovenous hemofiltration. J Clin Pharmacol 2005, 45:168-176.

76. Matzke GR, Frye RF, Joy MS, Palevsky PM: Determinants of ceftriaxone clearance by continuous venovenous hemofiltration and hemodialysis. Pharmacotherapy 2000, 20:635-643.

77. Kroh UF, Lennartz H, Edwards DJ, Stoeckel K: Pharmacokinetics of ceftriaxone in patients undergoing continuous veno-venous hemofiltration. J Clin Pharmacol 1996, 36:1114-1119.

78. Bouman CSC, van Kan HJM, Koopmans RP, Korevaar JC, Schultz MJ, Vroom MB: Discrepancies between observed and predicted continuous venovenous hemofiltration removal of antimicrobial agents in critically ill patients and the effects on dosing. Intens Care Med 2006, 32:2013-2019.

79. Meyer B, el GS A, Delle KG, Locker GJ, Heinz G, Jaeger W, Thalhammer F: How to calculate clearance of highly protein-bound drugs during continuous venovenous hemofiltration demonstrated with flucloxacillin. Kidney Blood Press Res 2003, 26:135-140.

80. Choi G, Gomersall CD, Tian Q, Joynt GM, Freebairn R, Lipman J: Principles of antibacterial dosing in continuous renal replacement therapy. Crit Care Med 2009, 37:2268-2282.

81. Schetz M, Ferdinande P, Van den Berghe G, Verwaest C, Lauwers P: Pharmacokinetics of continuous renal replacement therapy. Intensive Care Med 1995, 21:612-620.

82. Isla A, Gascon AR, Maynar J, Arzuaga A, Sanchez-Izquierdo JA, Pedraz JL: In vitro AN69 and polysulphone membrane permeability to ceftazidime and in vivo pharmacokinetics during continuous renal replacement therapies. Chemotherapy 2007, 53:194-201.

83. Isla A, Maynar J, Sanchez-Izquierdo JA, Gascon AR, Arzuaga A, Corral E, Pedraz JL: Meropenem and continuous renal replacement therapy: in vitro permeability of 2 continuous renal replacement therapy membranes and influence of patient renal function on the pharmacokinetics in critically ill patients. J Clin Pharmacol 2005, 45:1294-1304

84. Seyler L, Cotton F, Taccone FS, De Backer D, Macours P, Vincent $J$, Jacobs $F$ : Recommended beta-lactam regimens are inadequate in septic patients treated with continuous renal replacement therapy. Crit Care 2011, 15:R137.

85. Grill MF, Maganti RK: Neurotoxic effects associated with antibiotic use: management considerations. Brit J Clin Pharmaco 2011, 72:381-393.

86. Giles $L$, Jennings $A C$, Thomson AH, Creed G, Beale RJ, McLuckie A: Pharmacokinetics of meropenem in intensive care unit patients receiving continuous veno-venous hemofiltration or hemodiafiltration. Crit Care Med 2000, 28:632-637.

87. Robatel C, Decosterd LA, Biollaz J, Eckert P, Schaller MD, Buclin T: Pharmacokinetics and dosage adaptation of meropenem during continuous venovenous hemodiafiltration in critically ill patients. J Clin Pharmacol 2003, 43:1329-1340.

88. Ververs TF, van Dijk A, Vinks SA, Blankestijn PJ, Savelkoul JF, Meulenbelt J, Boereboom FT: Pharmacokinetics and dosing regimen of meropenem in critically ill patients receiving continuous venovenous hemofiltration. Crit Care Med 2000, 28:3412-3416.

89. Thalhammer F, Schenk P, Burgmann H, El Menyawi I, Hollenstein UM, Rosenkranz AR, Sunder-Plassmann G, Breyer S, Ratheiser K: Single-dose pharmacokinetics of meropenem during continuous venovenous hemofiltration. Antimicrob Agents Chemother 1998, 42:2417-2420.

90. Valtonen M, Tiula E, Takkunen O, Backman JT, Neuvonen PJ: Elimination of the piperacillin/tazobactam combination during continuous venovenous haemofiltration and haemodiafiltration in patients with acute renal failure. J Antimicrob Chemother 2001, 48:881-885.

91. Mueller SC, Majcher-Peszynska J, Hickstein H, Francke A, Pertschy A, Schulz M, Mundkowski R, Drewelow B: Pharmacokinetics of piperacillintazobactam in anuric intensive care patients during continuous venovenous hemodialysis. Antimicrob Agents Chemother 2002, 46:1557-1560

92. Dasgupta A: Introduction to Therapeutic Drug Monitoring. In Handbook of Drug Monitoring Methods: Therapeutics and Drugs of Abuse. Edited by Dasgupta A. New Jersey: Humana Press Inc; 2008:1-39. 
93. Dasgupta A: Introduction to Therapeutic Drug Monitoring and Chromatography. In Advances in Chromatographic Techniques for Therapeutic Drug Monitoring. Edited by Dasgupta A. Boca Raton: CRC Press Taylor and Francis Group, LLC; 2010:1-38.

94. Lam S, Gomolin $H_{\text {: }}$ Cefepime neurotoxicity: case report, pharmacokinetic considerations, and literature review. Pharmacotherapy 2006, 26:1169-1174

95. Ye R-H, Lin M-Y, Sung C-C, Lin S-H: Standard Dose of Piperacillin Induced Neurotoxicity in Advanced Renal Failure. Acta Nephrologica 2011, 25:89-92.

96. Huang W-T, Hsu Y-J, Chu P-L, Lin S-H: Neurotoxicity Associated with Standard Doses of Piperacillin in an Elderly Patient with Renal Failure. Infection 2009, 37:374-376.

97. Chow KM, Hui AC, Szeto CC: Neurotoxicity induced by beta-lactam antibiotics: from bench to bedside. Eur J Clin Microbiol Infect Dis 2005, 24:649-653.

98. Conil J-M, Georges B, Mimoz O, Dieye E, Ruiz S, Cougot P, Samii K, Houin G, Saivin S: Influence of renal function on trough serum concentrations of piperacillin in intensive care unit patients. Intens Care Med 2006, 32:2063-2066.

99. Roberts JA, Ulldemolins M, Roberts MS, McWhinney B, Ungerer J, Paterson DL, Lipman J: Therapeutic drug monitoring of beta-lactams in critically ill patients: proof of concept. Int J Antimicrob Ag 2010, 36:332-339.

100. Blondiaux N, Wallet F, Favory R, Onimus T, Nseir S, Courcol RJ, Durocher A, Roussel-Delvallez M: Daily serum piperacillin monitoring is advisable in critically ill patients. Int J Antimicrob Agents 2010, 35:500-503.

101. Pea F, Cojutti P, Sbrojavacca R, Cadeo B, Cristini F, Bulfoni A, Furlanut M: TDM-guided therapy with daptomycin and meropenem in a morbidly obese, critically ill patient. Ann Pharmacother 2011, 45:e37.

102. Taccone FS, Cotton F, Roisin S, Vincent JL, Jacobs F: Optimal meropenem concentrations to treat multidrug-resistant Pseudomonas aeruginosa septic shock. Antimicrob Agents Ch 2012, 56:2129-2131.

103. Patel BM, Paratz J, See NC, Muller MJ, Rudd M, Paterson D, Briscoe SE, Ungerer J, McWhinney BC, Lipman J, Roberts JA: Therapeutic Drug Monitoring of Beta-Lactam Antibiotics in Burns Patients-A One-Year Prospective Study. Ther Drug Monit 2012, 34:160-164.

104. Connor MJ Jr, Salem C, Bauer SR, Hofmann CL, Groszek J, Butler R, Rehm SJ, Fissell WH: Therapeutic drug monitoring of piperacillin-tazobactam using spent dialysate effluent in patients receiving continuous venovenous hemodialysis. Antimicrob Agents Chemother 2011, 55:557-560

105. Craig WA: Interrelationship between pharmacokinetics and pharmacodynamics in determining dosage regimens for broad-spectrum cephalosporins. Diagn Microbiol Infect Dis 1995, 22:89-96.

106. Drusano GL: Prevention of resistance: a goal for dose selection for antimicrobial agents. Clin Infect Dis 2003, 36:S42-S50.

107. Mouton JW, den Hollander JG: Killing of Pseudomonas aeruginosa during continuous and intermittent infusion of ceftazidime in an in vitro pharmacokinetic model. Antimicrob Agents Chemother 1994, 38:931-936.

108. Tam VH, Schilling AN, Neshat S, Poole K, Melnick DA, Coyle EA: Optimization of meropenem minimum concentration/MIC ratio to suppress in vitro resistance of Pseudomonas aeruginosa. Antimicrob Agents Chemother 2005, 49:4920-4927.

109. Roberts JA, Lipman J: Pharmacokinetic issues for antibiotics in the critically ill patient. Crit Care Med 2009, 37:840-851. quiz 859.

110. Verdier MC, Tribut O, Tattevin P, Le Tulzo Y, Michelet C, Bentue-Ferrer D: Simultaneous determination of 12 beta-lactam antibiotics in human plasma by high-performance liquid chromatography with UV detection: application to therapeutic drug monitoring. Antimicrob Agents Chemother 2011, 55:4873-4879.

111. McWhinney BC, Wallis SC, Hillister T, Roberts JA, Lipman J, Ungerer JP: Analysis of 12 beta-lactam antibiotics in human plasma by HPLC with ultraviolet detection. J Chromatogr B Analyt Technol Biomed Life Sci 2010, 878:2039-2043.

112. Morris RG, Tett SE, Ray JE: Cyclosporin A monitoring in Australia: consensus recommendations. Ther Drug Monit 1994, 16:570-576.

113. Ahrer W, Scherwenk E, Buchberger W: Determination of drug residues in water by the combination of liquid chromatography or capillary electrophoresis with electrospray mass spectrometry. J Chromatogr A 2001, 910:69-78.
114. Van Emon JM, LG C: Environmental monitoring and human exposure assessment using immunochemical techniques. J Microbiol Methods 1998, 32:121-131.

115. Norris RL, Martin JH, Thompson E, Ray JE, Fullinfaw RO, Joyce D, Barras M, Jones GR, Morris RG: Current status of therapeutic drug monitoring in Australia and New Zealand: a need for improved assay evaluation, best practice guidelines, and professional development. Ther Drug Monit 2010, 32:615-623.

116. Smith PF, Petros WP, Soucie MP, Copeland KR: New modified fluorescence polarization immunoassay does not falsely elevate vancomycin concentrations in patients with end-stage renal disease. Ther Drug Monit 1998, 20:231-235.

117. Benito-Pena E, Moreno-Bondi MC, Orellana G, Maquieira A, van Amerongen A: Development of a novel and automated fluorescent immunoassay for the analysis of beta-lactam antibiotics. J Agric Food Chem 2005, 53:6635-6642.

118. Usleber E, Litz S, Martlbauer E: Production and characterization of groupspecific antibodies against penicillin antibiotics. Food Agric Immunol 1998, 10:317-324.

doi:10.1186/2110-5820-2-35

Cite this article as: Sime et al:: Does Beta-lactam Pharmacokinetic Variability in Critically III Patients Justify Therapeutic Drug Monitoring? A Systematic Review. Annals of Intensive Care 2012 2:35.

\section{Submit your manuscript to a SpringerOpen ${ }^{\circ}$ journal and benefit from:}

- Convenient online submission

- Rigorous peer review

- Immediate publication on acceptance

- Open access: articles freely available online

- High visibility within the field

- Retaining the copyright to your article

Submit your next manuscript at $>$ springeropen.com 